\title{
A Preliminary Examination on the Multimedia Information Needs and Web Searches of College Students in Korea*
}

\begin{tabular}{|l|l|}
\hline 1. Introduction & EunKyung Chu \\
2. Related Studies & Searching \\
3. Methods & 5. Discussion \\
4. Results & 5.1 Intended multimedia uses \\
4.1 Characteristics of study & 5.2 Multimedia searching sources \\
participants & 5.3 Multimedia relevance criteria \\
4.2 Image information needs and & 5.4 Multimedia searching barriers \\
searching & 6. Conclusion \\
4.3 Audio information needs and & \\
searching & \\
\hline
\end{tabular}

\begin{abstract}
Multimedia searching is an important activity on the Web, especially among the younger generation. The purpose of this study aims to examine college students' multimedia information needs and searching on the Internet. While there is a clear pattern among students with respect to their multimedia uses, searching sources, relevance criteria and searching barriers, some differences exist especially according to searching of different multimedia types such as image, audio and video. For multimedia uses, information/data-focused uses are frequently found in image and video, while the use of audio is mainly for object-focused searches. As multimedia searching sources, audio and video files present a similar pattern of being high in media specific searching sources and low in generic search engines. Browsing through related blogs and homepages is an important part of searching for media files accounting for approximately $20 \%$ of total search for each media. The relevance criteria used by study participants when search for image files was primarily concerned with topicality while the contextual and media quality in the audio and video types are also considered important. Searching barriers for audio and video files are categorized into three broad aspects, including access and search quality, preview limitations and collection limitations, while obstacles for image files searching include access difficulties and low qualities of various collection.

Keywords: Multimedia, Information Needs, Information Seeking Behavior, Relevance Criteria, Seeking Barriers

* This work was supported by the National Research Foundation of Korea Grant funded by the Korean Government(NRF-2010-332-H00008).

The paper was originally presented at the International Conference commemorating the 40th Anniversary of the Korean Society for Library and Information Science held in Seoul, Korea on October 8, 2010.

** Department of Library and Information Science, Ewha Womans University(echung@ewha.ac.kr) 논문접수일자: 2010년 9월 7일 최초심사일자: 2010년 9월 16일 게재확정일자: 2010년 11월 15일 한국문헌정보학회지, 44(4): 95-114, 2010. [DOI:10.4275/KSLIS.2010.44.4.095]
\end{abstract}




\section{Introduction}

As improved digital technologies and networks have been available, creation, dissemination, access and use of multimedia information have become a part of everyday life activities. Multimedia searching has become an important activity for users since users' searches have diversified from entertainment to various human interests including medical and technology (Tjondronegoro, \& Spink, 2009). While multimedia information retrieval is considered one of the most active areas of research, the way of accessing multimedia information in practiceis little progress. Users mainly use text in order to search multimedia information even though there is no or little associated text (O'Connor, O'Connor, \& Abbas, 1999; Tjondronegoro, Spink, \& Jansen, 2009). Although increasing demands on multimedia on the Web have been for image, audio, and video, research on why users search multimedia, for what users use multimedia, and how users search multimedia on the Web has been little known. Research related to multimedia search has focused on is mainly query analysis type of studies in terms of individual media types. More importantly, while a number of studies have examined multimedia information needs and searching, there has been little known on multimedia needs and searching among a younger generation such as college students. College students can be a representative generation with technology and internet savvy. Most college students do have tendency to search multimedia and/or textual documents when they have information needs.

In this sense, in context of a young generation, in order to understand users' needs and searching on the Web for multimedia, the searches including image, audio and video needs to be studied in terms of a holistic view. The body of knowledge on multimedia information needs and searching on the Web may be increased with a view on how users search and use multimedia. The findings of this study can impact the design of multimedia search engines and indexing mechanism in order to improve the environment in which users search and have relevant results of multimedia.

Multimedia information can be defined as information entities comprising different media including audio, image, video, and text (Jaimes, Christel, Gilles, Sarukkai, \& Ma, 2005). With focusing on college students, the current study is part of a larger, ongoing research project to investigate multimedia information needs and searching on the Web of a young generation in Korea. The purpose of this current study aims to examine multimedia information needs among college students who actively use multimedia information in everyday life. To this end, the research objectives are set forth: (1) the overall understanding of multimedia needs and 
searching on the Web among college students, (2) the distinctive characteristics and features of multimedia information needs and searching depending on the types of media on the Web among college students.

\section{Related Studies}

At the aggregate level, there have been research endeavors on examining individual types of multimedia information needs and searching in terms of various users groups and contexts. Primary clusters of these research efforts can be divided into two: the studies on multimedia without focusing on specific types of multimedia and the studies on individual media type such as image, audio, and video. First, multimedia information needs and searching have been studied mainly in terms of search query analysis on the Web (Ozmutlu, Spink, \& Ozmutlu, 2003; Jansen, Spink, \& Pedersen, 2004; Tjondronegoro, \& Spink, 2009). On the other hand, individual multimedia information types such image, audio, and video have been studied. As image has been found primary media for searching on the Web (Tjondronegoro, \& Spink, 2009), substantial studies have been conducted in order to understand image information needs and search behavior. On the other, research on audio media has been recognized mainly for music materials (McPherson, \& Bainbridge, 2001; Itoh, 2000; Park, 2010). Recently, as video sharing sites (e.g., Youtube) has become popular, research on video information needs and searching on the Web has been conducted substantially. Consequently, four categories of studies are discussed in reviewing the related research to this current study.

First, multimedia search is considered as complex. Multimedia search query trends have been discussed during a period of 1997-2001 by Ozmutlu, Spink, and Ozmutlu (2003). In this study, they pointed out that while web searching on the Web was changing rapidly in terms of shorter query sessions and fewer query reformulation, more terms in a singlequery were used. When comparing general Web searching, multimedia Web searching was relatively complicated with a longer average query length and higher use of advanced search functions (Jansen, Spink, \& Pedersen, 2004). Recently, the trend analysis of multimedia Web searching by Tjondronegoro and Spink (2009) indicates that multimedia searching is short with less than one minute and its primary topic is about people. When compared with logs data from earlier years, the topics for searching multimedia have been changed from entertainment to various human interests such as medical, sports, and technology. By contrast, an analysis on multimedia search behavior 
in the context of a Korean portal site indicates that users are likely to search more music than image and video, and after searching, users view more video than image and audio. The primary topic in Korean portal sites and search engines for multimedia searching is for entertainment (Park, 2010).

Second, for image searches, a large body of research has been conducted in terms of analyzing image requests and search queries. Research on image needs and searching behavior from general users' group with non domain-specific collections is in a similar line to this current study. As one of the earliest efforts, Enser and McGregor (1993) examined 2,722 image requests to the non domain-specific collection from a wide variety of users. With categorizing users request in four types such as unique, unique with refiners, non-unique, and non-unique with refiners, approximately 70\% of image requests are in a unique category. On the Web, Goodrum and Spink (2001) analyzed the image search queries from the Excite search engine. They identified that image searching requires more terms and more unique terms in users queries compared to text searching. Recently, Jansen (2008) identified that users on the Web are more likely to search image from generic needs rather than specific needs, which is a different result from specific groups of users such as History, Art, and Publication areas. In a more naturalistic image searching environment, Cunningham, Bainbridge, and Masoodian (2004) analyzed 404 questions from visual arts category posted in Google Answers. The findings indicate that bibliographic and contents (e.g. literal object, people and event) categories were most described in users' questions. In a similar line of research, Cunningham and Masoodian (2006) analyzed 64 image request questions recollected from 31 college students in order to users' image search behavior. According to the Batley (1988)'s four image information needs, specific needs were most requested and followed by nameable needs (12.5\%) and subjective needs (12.5\%), respectively.

Third, most of studies for audio information were on music information needs and searching. McPherson and Bainbridge (2001) analyzed the search logs of music digital library called MELDEX. The primary finding of McPherson and Bainbridge's study indicates that users are more likely to search music by query searching (70\%) than by categorical browsing (30\%). Itoh (2000) analyzed search logs in the music library OPAC in order to provide appropriate access points for music searches. The analysis on a total of 21,177 sessions of music searching indicates that users tend to combine multiple more than two access points with various combinations of access points depending on users' needs for music. In order to elicit music information needs, an ethnographical study on how users search music was conducted in the 
context of music CD shops and the public library (Cunningham, Reeves, \& Britland, 2003). One of primary findings of Cunningham, Reeves and Britland's study pointed out that searching and browsing were interrelated, whereas visual aspect of music CD was found an important relevance criterion. With focusing on users' lifestyle, Taheri-panah and MacFarlane (2004) presented that users tend to search music in terms of known item searches such as song title and lyrics. Recently, given the context of natural language queries for searching music, Lee (2010) identified user needs for music in terms of features using a data set from a social Q\&A service. Lee indicated that users tend to search by known-item searches with a wide variety of features including person name, title, and genre.

Fourth, Huurnink, Hollink, Heuvel, and Rijke (2010) reported a transaction log analysis at alarge and national audiovisual archive for news producers, documentary makers, and other media professionals. While most of users' queries for video materials were found as title and proper names, there is a strong demand for short pieces of video materials. Given the context of professional settings, Christel (2007) analyzed transaction logs and questionnaire of an experimental and content-based video retrieval system in which government intelligent analysts use for their tasks. More than half of users used detectors which automatically identify visual objects and events in video. Yang and Marchionini (2004) explored relevance criteria for video in context of work-related searching tasks. Three categories of video relevance criteria were identified, textual, visual, and implicit categories. While topicality in textual category is the most important criterion, users tend to perceive barriers when they are allowed to search video only through textual information. Although users in the profession related setting are likely to search video by visual features such as object/event and motion, most video retrieval systems do not employ such mechanism to support visual features. Cunningham and Nichols (2008) reported video information needs and seeking strategies among colleges' students in New Zealand. The top four categories users search for video are music, humor, movies, and TV, while the top video source is found as Youtube.com.

\section{Methods}

The purpose of this study is to investigate multimedia information needs among a younger generation. Toward this end, this current study took two steps in terms of data collection. As the first step of this current study, to develop a survey instrument method, a pilot study was 
conducted. The pilot study consists of an open-ended questionnaire containing three categories of questions: image, audio and video information needs and searching behaviors on the Web. The pilot study was administrated in the class of "Human Computer Interaction" which is a graduate class offered by the department of Library and Information Science at the Ewha Womans University on June 2, 2010. The participants of the pilot study were asked to answer open-ended questions regarding image/audio/video use, searching sources, relevance criteria and searching barriers, respectively. A total of 41 responses in the pilot study were content analyzed in order to frame the relevant answers for the survey instrument. At the second step, the survey instrument developed by the pilot study was administrated. The participants of this study were randomly recruited from library users at the Soongsil University, a private university in Seoul, during the period of July 5 through July 30, 2010. Once pre-tested, the survey tool was administrated to 500 students from which 165 sets of responses were usable for analysis. The survey instrument consists of three sections of questions regarding image, audio and video information needs and information behavior on the Web. Each participant was then asked to choose an answer or multiples answers depending on questions. The results of surveywere analyzed in terms of three media types.

\section{Results}

\subsection{Characteristics of study participants}

The 165 responses were analyzed for examining multimedia information needs and information behavior of college students. 〈Table 1〉 shows the demographic information and characteristics of the study participants. The participants are primarily a younger generation with technology acumen, and regularity of computer and multimedia access and use. As shown in $\langle$ Table 1〉, most of participants are 19 to 25 years old and undergraduate students. While the ratio of female and male students among respondents is similar to each other, the distribution of academic major indicates three primary areas such as Liberal Arts, Social Sciences and Engineering. While most of participants use the Web 6 to 20 hours per week on average, 28 participants (17.3\%) use more than 20 hours per week. In fact, the demographic characteristics specify the participants as a younger generation with sufficient Web searching experiences in everyday life. 
$\langle$ Table 1〉 Demographic information of the study participants

\begin{tabular}{|c|c|c|c|}
\hline \multicolumn{2}{|c|}{ Item } & Freq. & $\%$ \\
\hline \multirow{4}{*}{ Age } & 19-25 years old & 125 & 77.6 \\
\hline & 26-35 years old & 36 & 22.4 \\
\hline & $36-45$ years old & 0 & 0.0 \\
\hline & Over 45 years old & 0 & 0.0 \\
\hline \multirow{2}{*}{ Gender } & Female & 76 & 47.2 \\
\hline & Male & 85 & 52.8 \\
\hline \multirow{5}{*}{ Educational background } & Undergraduate student & 146 & 90.7 \\
\hline & Bachelor degree & 10 & 6.2 \\
\hline & Graduate student & 5 & 3.1 \\
\hline & Master degree & 0 & 0.0 \\
\hline & Ph.D. degree & 0 & 0.0 \\
\hline \multirow{7}{*}{ Academic major } & Liberal Arts & 37 & 23.0 \\
\hline & Social Sciences & 49 & 30.4 \\
\hline & Natural Science & 16 & 9.9 \\
\hline & Engineering & 55 & 34.2 \\
\hline & Medicine & 1 & 0.6 \\
\hline & Arts & 2 & 1.2 \\
\hline & Others & 1 & 0.6 \\
\hline \multirow{4}{*}{$\begin{array}{c}\text { Average Web searching hour } \\
\text { (per week) }\end{array}$} & Under 5 hours & 49 & 30.4 \\
\hline & $6-20$ hours & 84 & 52.2 \\
\hline & 21-40 hours & 21 & 13.0 \\
\hline & Over 40 hours & 7 & 4.3 \\
\hline
\end{tabular}

More specifically, in order to see the multimedia searching experiences, the participants were asked to specify the average hours spent on image, audio, and video information respectively searching per week as shown in 〈Table 2〉. While average hours on searching multimedia information tend to be similar with mostly less than one hour per week, there are slight differences among different types of multimedia information. Users are likely to spend more time when searching video information compared to image and audio information. On the other hand, the distribution of hours spent on searching audio information is relatively less than hours on image and video information searching. Theoverall findings are exploredin terms of perceived nature of multimedia information types, relevance criteria and searching barriers. 
〈Table 2〉Multimedia searching experiences

\begin{tabular}{|c|c|c|c|}
\hline \multicolumn{2}{|c|}{ Item } & Freq. & $\%$ \\
\hline \multirow{5}{*}{$\begin{array}{l}\text { Image searching hour } \\
\text { (per week) }\end{array}$} & Under 1 hour & 97 & 57.4 \\
\hline & 1-2 hours & 56 & 33.1 \\
\hline & $2-4$ hours & 12 & 7.4 \\
\hline & Over 4 hours & 4 & 2.4 \\
\hline & Total & 165 & 100.0 \\
\hline \multirow{5}{*}{$\begin{array}{l}\text { Audio searching hour } \\
\quad \text { (per week) }\end{array}$} & Under 1 hour & 108 & 65.5 \\
\hline & $1-2$ hours & 39 & 23.6 \\
\hline & $2-4$ hours & 15 & 9.1 \\
\hline & Over 4 hours & 3 & 1.8 \\
\hline & Total & 165 & 100.0 \\
\hline \multirow{5}{*}{$\begin{array}{l}\text { Video searching hour } \\
\quad \text { (per week) }\end{array}$} & Under 1 hour & 82 & 49.7 \\
\hline & $1-2$ hours & 47 & 28.5 \\
\hline & $2-4$ hours & 28 & 17.5 \\
\hline & Over 4 hours & 8 & 4.8 \\
\hline & Total & 161 & 100.0 \\
\hline
\end{tabular}

\subsection{Image information needs and searching}

Image searching has been found the dominant media type searched on the Web consistently since 1997 according to a study result (Tjondronegoro, \& Spink, 2009). As there are various image uses from users, seven image uses were able to be depictedin view of Conniss, Ashford, and Graham (2000)'s seven classes of image use. When applying the two pole theory by Fidel (1997) and Westman (2009)'s indication on image uses, the distribution of seven image uses are listed in $\langle$ Table 3$\rangle$. As shown in $\langle$ Table 3$\rangle$, illustration, information processing, aesthetic uses are the top three, whereas information dissemination, learning, and emotive/persuasive uses are the least.

〈Table 3〉 The distribution of image use

\begin{tabular}{c|c|c}
\hline Image use & Freq. & $\%$ \\
\hline Information processing (IP) & 72 & 21.2 \\
\hline Information dissemination (ID) & 15 & 4.4 \\
\hline Learning (LE) & 24 & 7.1 \\
\hline Generation of idea (GE) & 18 & 5.3 \\
\hline Illustration (IL) & 111 & 32.7 \\
\hline Aesthetic use (AE) & 63 & 18.6 \\
\hline Emotive and persuasive (EM) & 34 & 0.0 \\
\hline Other & 2 & 100.0 \\
\hline Total & 339 &
\end{tabular}


As illustrated in terms of two pole theory with identifying two extreme poles, data and object poles, and their constituents based on the distribution of image uses, 〈Figure 1〉 shows that users tend to search image for object use, rather than information or data use. Among image uses in data pole, information processing use shows a distinctive proportion.

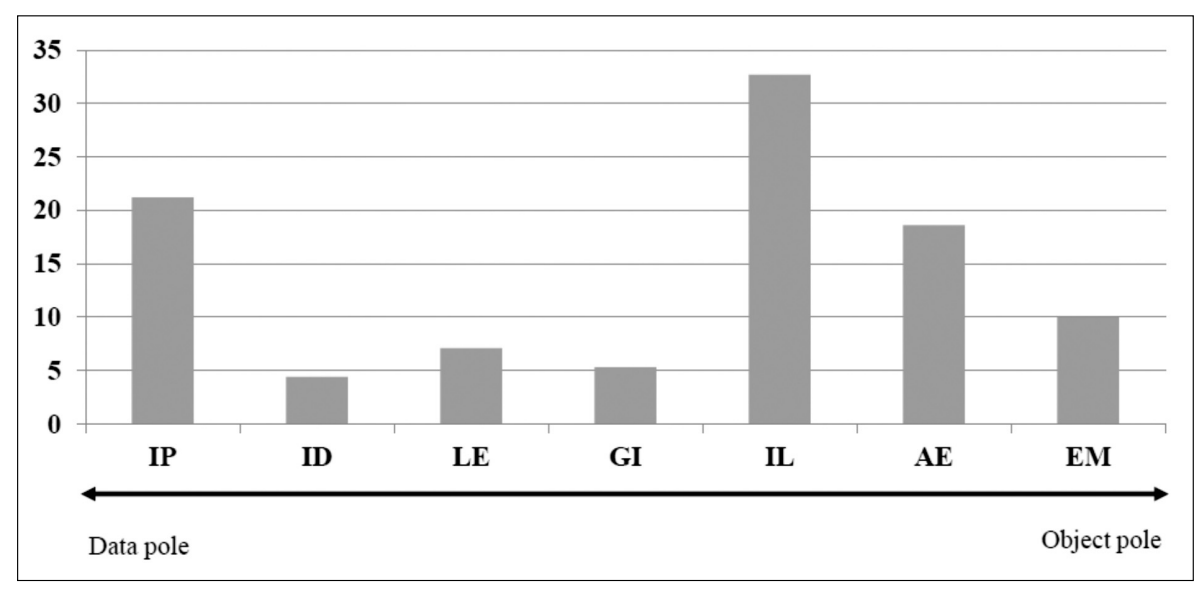

〈Figure 1〉 The distribution of image use depending on two poles

On the other hand, users' searching sources are identified as shown in 〈Table 4〉. In most, users tend to search images using Korean portals and general search engines. However, a substantial proportion (18.9\%) of users seeks images through browsing some related or known blogs/personal homepages.

$\langle$ Table 4〉 The distribution of image searching sources

\begin{tabular}{c|r|c}
\hline Image searching source & Freq. & $\%$ \\
\hline Korean portal (Naver, Daum, etc.) & 147 & 51.4 \\
\hline Search engine (Google, Yahoo, etc.) & 63 & 22.0 \\
\hline Image sharing site (Flickr, Picasa, etc.) & 8 & 2.8 \\
\hline Browsing blogs and homepages & 54 & 18.9 \\
\hline Related professional homepages & 12 & 4.2 \\
\hline Other & 2 & 0.7 \\
\hline Total & 286 & 100.0 \\
\hline
\end{tabular}

When users explore several images from the search results or from browsing, users tend to select an specific images among image search results based on some criteria as shown in 〈Table 
5). The relevance criteria for image can be classified in terms of three categories: topicality, context and media quality. For relevance criteria based on topicality, the most criterion users specified is whether the images are matched based on the topics. This finding supports that users are more likely to approach images in terms of semantics rather than visual aspects of image. From a perspective of media quality related relevance criteria, users are likely to select images based on whether the images are good quality or in high resolution. For a contextual aspect, the relevance criteria such as reliable sources are recognized in $5.9 \%$. Users tend to select based on whether images are from reliable sources such as newspaper sites and academic institutes,

$\langle$ Table 5〉 The distribution of image relevance criteria

\begin{tabular}{c|c|c}
\hline relevance criterion & Freq. & $\%$ \\
\hline Topicality & 138 & 51.1 \\
\hline Looking good & 62 & 23.0 \\
\hline Image captions & 25 & 9.3 \\
\hline Good quality & 28 & 10.4 \\
\hline Image from reliable source & 16 & 5.9 \\
\hline Other & 1 & 0.4 \\
\hline Total & 270 & 100.0 \\
\hline
\end{tabular}

As users search images on the Web, they usually recognize some barriers to image searching. Those barriers can be classified into three major categories: access, search quality and limitation on image collection. As shown in 〈Table 6〉, using three categories, in $32.9 \%$, users perceived irrelevant images in their search results as the biggest barrier. On the other hand, difficulties with access mechanism such as query formulation and keywords are recognized considerably.

〈Table 6〉 Image search barriers

\begin{tabular}{c|c|c}
\hline searching barriers & Freq. & $\%$ \\
\hline Difficult to choose proper keywords & 61 & 20.1 \\
\hline Difficult to formulate proper query sets & 73 & 24.0 \\
\hline Irrelevant images in search results & 100 & 32.9 \\
\hline Same images repeated & 57 & 18.8 \\
\hline Old images & 12 & 3.9 \\
\hline Other & 1 & 0.3 \\
\hline Total & 304 & 100.0 \\
\hline
\end{tabular}




\subsection{Audio information needs and searching}

The participants of this study specified two main audio uses: music listening and learning foreign language as shown in $\langle$ Table 7$\rangle$. The finding of this study supports that music searching is the top among audio search on the Web (Jansen, Goodrum, \& Spink, 2000). Other than music, participants of this study tend to search audio materials in order to learn foreign languages. The trend can be found distinctively since learning foreign language, especially spoken English, is important in the society.

$\langle$ Table 7〉 The distribution of audio use

\begin{tabular}{c|c|c}
\hline Audio use & Freq. & $\%$ \\
\hline Listen to music & 156 & 65.5 \\
\hline Learning foreign language & 66 & 27.7 \\
\hline Doing tasks & 12 & 5.0 \\
\hline Reading & 1 & 0.4 \\
\hline Others & 3 & 1.3 \\
\hline Total & 238 & 100.0 \\
\hline
\end{tabular}

With the use of audio, users tend to search audio in various sources as shown in 〈Table 8〉. While the primary audio use is identified as music searching, the sources for audio searching are diverse. More specifically, the preferences of searching sources are ranged from music searching site to browsing blogs and homepages. An interesting type of responses categorized in others is that users get music from friends rather than searching on the Web.

$\langle$ Table 8> The distribution of audio searching source

\begin{tabular}{c|c|c}
\hline Audio searching source & Freq. & $\%$ \\
\hline Music searching site & 57 & 19.7 \\
\hline Foreign language learning site & 19 & 6.6 \\
\hline P2P services & 93 & 32.1 \\
\hline Search engines & 51 & 17.6 \\
\hline Browsing blogs and homepages & 59 & 20.3 \\
\hline Others & 11 & 3.8 \\
\hline Total & 290 & 100.0 \\
\hline
\end{tabular}

As $\langle$ Table 9 $\rangle$ indicates, when users search audio materials, users are likely to select audio 
materials based on some criteria such as topicality and the cost of audio materials. In addition, the quality of audio and the popularity were recognized as significant factors when users judge.

$\langle$ Table 9> The distribution of audio relevance criteria

\begin{tabular}{c|c|c}
\hline Audio searching source & Freq. & $\%$ \\
\hline Topicality & 78 & 31.0 \\
\hline Good quality & 44 & 17.5 \\
\hline Popularity & 49 & 19.4 \\
\hline Free of charge items & 72 & 28.6 \\
\hline Playing time is proper & 5 & 2.0 \\
\hline Other & 4 & 1.0 \\
\hline Total & 252 & 100.0 \\
\hline
\end{tabular}

When users search audio materials on the Web, three primary obstacles were identified. First, since there is little preview mechanism for audio materials, users have to select without appropriate representations of actual audio materials. In order to see if users need to decide whether audio materials are relevant or not, they have to listen to audio materials first. Second, in order to formulate proper queries, users felt that they have to know the file names or titles; otherwise users perceive that there are no other appropriate access points. Third, users felt that there were limited audio collections on the Web.

$\langle$ Table 10〉 The distribution of audio searching barriers

\begin{tabular}{c|c|c}
\hline Audio searching barriers & Freq. & $\%$ \\
\hline Inappropriate categorization & 13 & 5.5 \\
\hline Difficult to choose proper keywords & 21 & 8.9 \\
\hline Have to listen first & 80 & 33.8 \\
\hline Have to know at least file names or titles & 60 & 25.3 \\
\hline Limited audio materials on the Web & 55 & 23.2 \\
\hline Others & 8 & 3.4 \\
\hline Total & 304 & 100.0 \\
\hline
\end{tabular}

\subsection{Video information needs and searching}

Users primarily search video materials in order to watch movies and interesting current issues. While these two video uses account for approximately $66.5 \%$, a substantial proportion (24.2\%) 
of video use is found as learning use. Users search video materials in order to learn something out of it. This finding might lead to the design issues for video searching systems or engines since there may exist different access points to video materials between entertainment and learning.

$\langle$ Table 11〉 The distribution of video use

\begin{tabular}{c|c|c}
\hline Video use & Freq. & $\%$ \\
\hline Watch movies and TV shows & 131 & 42.3 \\
\hline Learning & 57 & 18.4 \\
\hline Get information & 27 & 8.7 \\
\hline Complement textual documents & 17 & 5.5 \\
\hline Watch interesting current issues & 75 & 24.2 \\
\hline Others & 3 & 1.0 \\
\hline Total & 310 & 100.0 \\
\hline
\end{tabular}

As in $\langle$ Table 12〉, when users search videos on the Web, they primarily search using four main sources including P2P site, video search site (e.g., Youtube), regular search engines and browsing through blogs and homepages.

〈Table 12〉 The distribution of video searching source

\begin{tabular}{c|c|c}
\hline Video searching source & Freq. & $\%$ \\
\hline Video searching site & 73 & 24.0 \\
\hline P2P site & 99 & 32.6 \\
\hline Search engines & 62 & 20.4 \\
\hline Browsing blogs and homepages & 56 & 18.4 \\
\hline Broadcasting company sites & 11 & 3.6 \\
\hline Others & 3 & 1.0 \\
\hline Total & 304 & 100.0 \\
\hline
\end{tabular}

As 〈Table 13〉 shows, for relevance criteria for videos, the topicality was found in a ratio of $32 \%$. Rather, the quality of video and contextual criteria such as popularity and cost were identified considerably. 
〈Table 13〉 The distribution of video relevance criteria

\begin{tabular}{c|c|c}
\hline Video relevance criteria & Freq. & $\%$ \\
\hline Topicality & 91 & 32.7 \\
\hline Good quality & 89 & 32.0 \\
\hline Popularity & 43 & 15.5 \\
\hline Free of charge items & 50 & 18.0 \\
\hline Playing time is proper & 3 & 1.1 \\
\hline Other & 2 & 0.7 \\
\hline Total & 278 & 100.0 \\
\hline
\end{tabular}

In general, users recognize video searching barriers in terms of access facilities, lack of preview features and limitation on collections as shown in 〈Table 14〉. The difficulties with access mechanism including categorization and keyword formulation are found in $26.1 \%$, while previewing difficulty is found substantially with $32.5 \%$. In addition, the limited collection of video is considered as a significant barrier (17.9\%).

$\langle$ Table 14〉 The distribution of video searching barriers

\begin{tabular}{c|c|c}
\hline Video searching barriers & Freq. & $\%$ \\
\hline Inappropriate categorization & 21 & 9.0 \\
\hline Difficult to choose proper keywords & 40 & 17.1 \\
\hline Have to watch first & 76 & 32.5 \\
\hline Have to know at least file names or titles & 48 & 20.5 \\
\hline Limited video materials on the Web & 42 & 17.9 \\
\hline Others & 7 & 3.0 \\
\hline Total & 234 & 100.0 \\
\hline
\end{tabular}

\section{Discussion}

As one of important searching activities on the Web among a younger generation, users' multimedia searching needs and behavior were examined using a survey instrument. A total of 165 responses were analyzed to explore users' intended uses, searching sources, relevance criteria and searching barriers for multimedia resources among college students. To understand the interwoven relationship between multimedia and behavioral aspects, comparative analyses among media types are discussed according to intended uses, searching sources, relevance 
criteria and searching barriers.

\subsection{Intended multimedia uses}

When users search multimedia, they are likely to have intended uses or purposes. The uses and purposes are considered as one of critical features affecting the users' needs and searching behavior on the Web. As shown in 〈Table 15〉, the comparison among three types of multimedia indicates that a considerable similarity is able to be perceived between image and video types. The types of video and image present a comparable pattern which contains a similar ratio between information/data focused uses and object-focused uses. Whereas multimedia uses in the audio type are found mostly in the object-focused uses, rather than in the information/ data-focused uses. Depending on the type of multimedia, users' intended uses can be distinguished in the view of a data and object-focused spectrum.

〈Table 15〉 The intended uses among image, audio and video

\begin{tabular}{|c|c|c|c|c|c|c|}
\hline Category & Image & $\%$ & Audio & $\%$ & Video & $\%$ \\
\hline \multirow{6}{*}{$\begin{array}{l}\text { Information/ } \\
\text { data-focused }\end{array}$} & Learning & 7.1 & Doing tasks & 5.0 & Learning & 18.4 \\
\hline & $\begin{array}{l}\text { Information } \\
\text { processing }\end{array}$ & 21.2 & Readings & 0.4 & $\begin{array}{l}\text { Getting } \\
\text { information }\end{array}$ & 8.7 \\
\hline & \begin{tabular}{|l|} 
Information \\
dissemination \\
\end{tabular} & 4.4 & & & $\begin{array}{l}\text { Watching current } \\
\text { issues }\end{array}$ & 24.2 \\
\hline & Generation of idea & 5.3 & & & & \\
\hline & Illustration & 32.7 & & & & \\
\hline & $\begin{array}{l}\text { Emotive and } \\
\text { persuasive } \\
\end{array}$ & 10.0 & $\begin{array}{l}\text { Learning foreign } \\
\text { languages }\end{array}$ & 27.7 & \begin{tabular}{|l|} 
Complementing \\
textual documents
\end{tabular} & 5.5 \\
\hline \multirow[t]{2}{*}{ Object-focused } & Aesthetic & 18.6 & Listening to music & 65.5 & $\begin{array}{l}\text { Watching } \\
\text { movies/TV shows }\end{array}$ & 42.3 \\
\hline & Others & 0.6 & Others & 1.3 & Others & 1.0 \\
\hline Total & & 100.0 & & 100.0 & & 100.0 \\
\hline
\end{tabular}

\subsection{Multimedia searching sources}

The multimedia searching sources can be categorized into media specific sources (e.g., Flickr site for image searching source) and generic sources such as general search engines. 〈Table 16) indicates that a similarity between audio and video, rather image. The multimedia types such as audio and video are likely to be searched in media specific searching sources, rather 
than generic sources, while images are searched using more general search engine. Given the average size of audio and video files, users show a similar pattern of searching sources between audio and video. On the other hand, the searching through browsing is found in similar proportions among image, audio and video. This finding indicates that browsing is still an important source of searching multimedia and frequently used sources are distinguished depending on media types.

〈Table 16〉 The searching sources among image, audio and video

\begin{tabular}{|c|c|c|c|c|c|c|}
\hline Category & Image & $\%$ & Audio & $\%$ & Video & $\%$ \\
\hline \multirow[t]{3}{*}{$\begin{array}{l}\text { Specific } \\
\text { sources }\end{array}$} & \begin{tabular}{|l|} 
Image sharing sites \\
Professional \\
homepages
\end{tabular} & $\begin{array}{l}2.8 \\
4.2\end{array}$ & $\begin{array}{l}\text { Music sites/ } \\
\text { Foreign language } \\
\text { learning sites }\end{array}$ & $\begin{array}{c}19.7 \\
6.6\end{array}$ & $\begin{array}{l}\text { Video searching sites } \\
\text { Broadcast company } \\
\text { sites }\end{array}$ & $\begin{array}{c}24.0 \\
3.6\end{array}$ \\
\hline & $\begin{array}{l}\text { Browsing through } \\
\text { blogs and homepages }\end{array}$ & 18.9 & $\begin{array}{l}\text { Browsing through } \\
\text { blogs and homepages }\end{array}$ & 20.3 & $\begin{array}{l}\text { Browsing through } \\
\text { blogs and homepages }\end{array}$ & 18.4 \\
\hline & $\mathrm{P} 2 \mathrm{P}$ & 0 & $\mathrm{P} 2 \mathrm{P}$ & 32.1 & $\mathrm{P} 2 \mathrm{P}$ & 32.6 \\
\hline \multirow[t]{2}{*}{ Generic sources } & $\begin{array}{l}\text { Portal sites } \\
\text { Search engines }\end{array}$ & 73.4 & Search engines & 17.6 & Search engines & 20.4 \\
\hline & Others & 0.7 & Others & 3.8 & Others & 1.0 \\
\hline Total & & 100.0 & & 100.0 & & 100.0 \\
\hline
\end{tabular}

\subsection{Multimedia relevance criteria}

When looking at the relevance criteria in terms of three categories such as topicality, context and media quality, there are some distinctive features depending on individual media types as shown in 〈Table 17〉. Topicality is considered most among image, audio and video, while media quality is most significant in video rather than image and audio. Although the constituent elements are different in context category, the significance of contextual information is identified.

〈Table 17〉 The relevance criteria among image, audio and video

\begin{tabular}{c|l|c|l|c|l|c}
\hline Category & \multicolumn{1}{|c|}{ Image } & $\%$ & \multicolumn{1}{c|}{ Audio } & $\%$ & \multicolumn{1}{|c}{ Video } & $\%$ \\
\hline \multirow{2}{*}{ Topicality } & Topicality & 51.1 & Topicality & 31.0 & Topicality & 32.7 \\
& Topic related image caption & 9.3 & & & & \\
\hline \multirow{3}{*}{ Context } & Reliable source & 5.9 & Popularity & 19.4 & Popularity & 15.5 \\
& Visual representation & 23.0 & Free & 28.6 & Free & 18.0 \\
& & & Play time & 2.0 & Play time & 1.1 \\
\hline Media quality & Good quality & 10.4 & Good quality & 17.5 & Good quality & 32.0 \\
\hline & Others & 0.4 & Others & 1.0 & Others & 0.7 \\
\hline Total & & 100.0 & & 100.0 & & 100.0 \\
\hline
\end{tabular}




\subsection{Multimedia searching barriers}

As shown in $\langle$ Table 18〉, multimedia searching barriers are identified into three categories such as access and search quality, preview limitation and collection limitation. While access and search quality are recognized highly in image searches, the limited preview feature is found as a substantial barrier with more than $32 \%$ both in audio and video. On the other hand, the collection limitation for three media types is identified as a common barrier.

$\langle$ Table 18〉 The searching barriers among image, audio and video

\begin{tabular}{|c|c|c|c|c|c|c|}
\hline Category & Image & $\%$ & Audio & $\%$ & Video & $\%$ \\
\hline $\begin{array}{c}\text { Access and search } \\
\text { quality }\end{array}$ & \begin{tabular}{|l|} 
Difficult to choose \\
proper keyword \\
Difficult to \\
formulate proper \\
query sets \\
Irrelevant images in \\
search results
\end{tabular} & $\begin{array}{l}20.1 \\
24.0\end{array}$ & \begin{tabular}{|l|} 
Inappropriate \\
categorization \\
Difficult to choose \\
proper keywords \\
Have to know at \\
least file names or \\
titles
\end{tabular} & $\begin{array}{r}5.5 \\
8.9 \\
25.3\end{array}$ & \begin{tabular}{|l|} 
Inappropriate \\
categorization \\
Difficult to choose \\
proper keywords \\
Have to know at \\
least file names or \\
titles
\end{tabular} & $\begin{array}{r}9.0 \\
17.1 \\
20.5\end{array}$ \\
\hline $\begin{array}{c}\text { Preview } \\
\text { limitation }\end{array}$ & & & Have to listen first & 33.8 & Have to watch first & 32.5 \\
\hline \multirow[t]{2}{*}{$\begin{array}{l}\text { Collection } \\
\text { limitation }\end{array}$} & $\begin{array}{l}\text { Same images } \\
\text { repeated } \\
\text { Old images }\end{array}$ & $\begin{array}{l}18.8 \\
3.9 \\
\end{array}$ & $\begin{array}{l}\text { Limited audio } \\
\text { materials on the } \\
\text { Web }\end{array}$ & 23.2 & $\begin{array}{l}\text { Limited video } \\
\text { material on the } \\
\text { Web }\end{array}$ & 17.9 \\
\hline & Others & 0.3 & Others & 3.4 & Others & 3.0 \\
\hline Total & & 100.0 & & 100.0 & & 100.0 \\
\hline
\end{tabular}

\section{Conclusion}

Among internet and technology savvy college students, multimedia searching is an important activity on the Web in a part of everyday life. The purpose of this study aims to examine young generation's multimedia information needs and searching on the Web. While there are overall features on multimedia uses, searching sources, relevance criteria and searching barriers on the Web, distinctive characteristics are recognized depending on multimedia types; image, audio and video. First, from a perspective of multimedia uses, information/data-focused uses are frequently found in image and video, while the use of audio is mainly for object-focused. This finding suggests that depending on media types, information features extracted from multimedia may be used differently. For instance, data-focused uses primarily require associated 
textual information in order to provide sufficient information. On the other hand, to meet the needs from object-oriented needs, features from object such as file size/type and output devices should be more concerned. Second, as multimedia searching sources, audio and video present a similar pattern which is high in media specific searching sources and low in generic search engines. More importantly, the browsing through related blogs and homepages is notable since it is recognized all three media types with a considerable portion (approximately 20\%). The identified diverse searching sources especially in audio and video may indicate that there are alternative searching sources for audio and video. Third, the relevance criteria for image primarily are topicality, while the contextual and media quality in the audio and video types are recognized substantially. This finding may indicate that access points from contextual information and physical quality of multimedia should be incorporated to meet the users' needs, especially for audio and video. Four, the searching barriers for audio and video are categorized into three broad aspects such as access and search quality and preview limitation and collection limitation, while ones in image are access difficulties and low qualities of collection. In order to reduce the searching barriers, the finding of this study may recommend that a better preview mechanism for audio and video should be designed and applied in practice.

\section{References}

[1] Batley, S. 1988. "Visual Information Retrieval: Browsing Strategies in pictorial database." Proceedings of the 12th International Online Information Meeting, 373-381.

[2] Cunningham, S.J., Bainbridge,D., \& Masoodian, M. 2004. "How people describe their image information needs: A grounded theory analysis of visual art queries." Proceedings of the Joint Conference for Digital Libraries, 47-48.

[3] Cunningham, S.J., Bainbridge, D., \& McKay, D. 2007. "Finding new music: a diary study of everyday encounter with novel songs." Proceedings of the 8th International Conference on Music Information Retrieval, Vienna, Austria, September 23-27, 83-88.

[4] Cunningham, S.J., \& Masoodian, M. 2006. "Looking for a picture: An analysis of everyday image information searching." Proceedings of the Joint Conference for Digital Libraries, 198-199.

[5] Cunningham, S.J., Reeves, N., \& Britland, M. 2003. “An ethnographic study of music 
information seeking: implications for the design of a music digital library." The Proceedings of Joint Conference on Digital Libraries, 5-17.

[6] Enser, P., \& McGregor, C. 1993. Analysis of visual information retrieval queries. British Library Research and Development Report 6104.

[7] Goodrum, A., \& Spink, A. 2001. "Image searching on the Excite Web search engine." Information Processing and Management, 37(1): 295-311.

[8] Itoh, M. 2000. "Subject search for music: Quantitative analysis of access point selection." International Symposium on Music Information Retrieval.

[9] Jaimes, R., Christel, M., Gilles, S., Sarukkai, R., \& Ma, W. 2005. "Multimedia information retrieval: What is it, and why isn't anyone using it." ACM Multimedia Workshop on MIR.

[10] Jansen, B.J. 2008. "Searching for digital images on the web." Journal of Documentation, 64(1): 81-101.

[11] Jasen, B.J., Spink, A., \& Peterson, J. 2003. "An analysis of multimedia searching on Alta Vista." Proceedings of the 5th ACM SIGMM International Workshop on Multimedia Information Retrieval, 186-192.

[12] Jansen, B.J., Goodrum, A., \& Spink, A. 2000. "Searching for multimedia: analysis of audio, video, and image Web queries." World Wide Web Journal, 3(4): 249-254.

[13] Lee, J.H. 2010. "Analysis of users needs and information features in natural language queries seeking music information." Journal of the American Society for Information Science and Technology, 61(5): 1025-1045.

[14] McPherson, J., \& Bainbridge, D. 2001. "Usage of the MELDEX Digital Music Library." The Proceedings of International Symposium on Music Information Retrieval, 15-17.

[15] O’Connor, B., O'Connor, M, \& Abbas J. 1999. "User reactions as access mechanism: an exploration based on captions for images." Journal of the American Society for Information Science, 50(8): 681-697.

[16] Oritz, S. Jr. 2007. "Searching the visual Web." Computer, 40(6): 12-14.

[17] Ozmutlu, S., Spink, A., \& Ozmutlu, H.C. 2003. "Multimedia Web searching trends: 19972001." Information Processing \& Managment, 39(4): 611-621.

[18] Park, S. 2010. "The multimedia searching behavior of Korean portal users." Journal of the Korean Society for Library and Information Science, 44(1): 101-115.

[19] Spink, A., \& Jansen, B.J. 2006. "Searching multimedia federated content Web collections." Online Journal Review, 30(5): 485-495.

[20] Taheri-panah, S., \& Macfarlane, A. 2004. "Music information retrieval systems: why do 
114 한국문헌정보학회지 제 44 권 제 4 호 2010

individuals use them and what are their needs." International Symposium on Music Information Retrieval.

[21] Tjondronegoro, D., Spink, A., \& Jansen, B.J. 2009. "A study and comparison of multimedia web searching: 1997-2006." Journal of the American Society for Information and Technology, 60(9): 1756-1768. 